\title{
La arquitectura de la información del siglo XX al XXI
}

\author{
Por Jesús Bustamante
}

CUANDO RICHARD SAUL WURMAN acuñó el término "arquitectura de la información" en 1976, lo hizo para describir lo que percibía entonces como una profesión emergente, la cual se ocuparía de aclarar lo complejo y de organizar "el $t$ sunami de datos que rompe en las playas del mundo civilizado"'. Una profesión del futuro.

Hoy parece que los años dorados de la arquitectura de la información son cosa del pasado. Quien así piensa argumenta que lo poco o mucho que se había conseguido lo borró del mapa la explosión de la burbuja del .com del año 2000 (un auténtico tsunami también, por cierto). ¡Visto y no visto, señores!

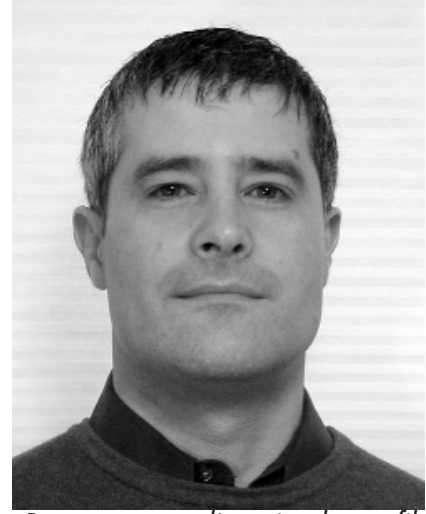

Jesús Bustamante es licenciando en filosofía por la Universidad Complutense de Madrid y Master of arts in library and information science de la Universidad de Wisconsin-Madison. Co-Presidente y fundador de Camino Project Inc., ha aplicado sus conocimientos de tecnología, usabilidad y organización de la información al diseño de estructuras de información para clientes como Coca-Cola Enterprises Inc., Jenner \& Block, Packaging Corporation of America, Motorola, Prime Group Realty Trust, Mark Shale, etc.
Toda una vida en tiempo de internet, pero un pis-pas en tiempo real.

Sea cosa del pasado o del porvenir, la historia (o anécdota) de la "arquitectura de la información" ilustra muy bien desde mi punto de vista la constante lucha del profesional de la información por alcanzar reconocimiento profesional. Así, para quien no haya visto muy bien la jugada, querría rebobinar un poco la cinta y pasarla un poquito más despacio. Los acontecimientos que se refieren a continuación son la historia según me fue a mí en ella...

\section{La gorra del capitán. Desde 1995 a finales del 2000}

Wurman se sorprendió de que la arquitectura de la información no prendiera immediatamente (cual reguero de pólvora). 20 años más tarde se sorprende de nuevo cuando salen arquitectos de la información por debajo de las piedras. La aparición del web en 1994 y su implantación fulgurante, da cuenta sin más de la diferencia entre un momento y otro.

Aquellos especialistas de la información que en la primera mitad de los noventa caímos en el torbellino del web, vimos también en este medio una buena oportunidad profesional. Nos llamamos entonces "webmasters" (huevomaestros) o cualquier cosa impronunciable que nos quisieran llamar con tal de poder seguir jugando con nuestros web sites.

\section{«La gozosa pomposi- dad del término 'ar- quitectura' se la de- bemos al hecho de que Mr. Wurman es arquitecto por forma- ción académica»}

El título de "arquitecto de la información" nos vino al pelo. Como si un capitán se hubiera dejado la gorra y las medallas olvidadas encima de la mesa, nos plantamos el uniforme y nos unimos al desfile sin darle explicaciones a nadie. La gozosa pomposidad del término "arquitectura" se la debemos al hecho de que Wurman es arquitecto por formación académica. Y muy agradecidos que le estamos, porque sin el vestido largo quizá no nos hubieran invitado al baile.

Estos son los años dorados de la arquitectura de la información. En esta disciplina se reúnen profesionales de una gran variedad de pelajes académicos y profesionales, desde la biblioteconomía hasta el diseño industrial, pasando por HCI (human computer interaction). Las empresas de internet nos buscan y los arquitectos de la información nos dejamos querer. El término se usa hasta tal punto, que comienza a hacerse frecuente la abreviatura "ia" (information architecture), como si se tratase de un carnet de club exclusivo, o co- 
mo si todo el mundo estuviese al corriente...

Hitos de esta época incluyen:

Argus Associates, Inc. Aparece como una empresa dedicada exclusivamente a la arquitectura de la información. En 1998, sus líderes (Peter Morville y Lou Rosenfeld) publican Information architecture for the world wide web $b^{2}$ y el libro verde del oso polar (como también se le conoce) se convierte en la cabecera de la avanzadilla.

Se crean y crecen rápidamente las consultorías especializadas en desarrollo de web. Empresas como Sapient, Scient, Viant, Agency.com, IXL, MarchFirst, Rare Medium, Zefer, Luminant, etc., acogen formalmente a la arquitectura de la información como disciplina. Un arquitecto de la información con poca experiencia laboral (o ninguna) podría comenzar ganando entre 40.000 US\$ y 50.000 US\$ al año. Se mandan imprimir tarjetas de visita con el título "arquitecto de información" y se incorporan a departamentos como el de estrategia, tecnología, o el de diseño creativo. En otros casos (quizá los menos) se crean departamentos de arquitectura de información como tales. Tal fue el caso del grupo que yo creé y dirigí en el Web Design Group, Inc. de Chicago.

Estos años dorados culminan con la primera conferencia de y para arquitectos de la información (Information architecture 2000), que tuvo lugar en San Diego (California) en octubre del año 2000. Allí nos reunimos, charlamos, nos dimos palmaditas en la espalda y comimos canapés. Aunque ya venían pelando barbas, ninguno parecía tener el menor interés en poner la suya a remojar.

\section{EI canario en la mina. El año 2001}

En el año 2001 explotó la burbuja especulativa de internet y caen

las empresas de tecnología en la bolsa. Entre finales de marzo y mediados de abril el Nasdaq perdió un tercio de su valor. La inversión desaparece por completo. Argus Associates Inc., que no hacía un año que había apostado por crecer, no pudo mantenerse en un mercado que se contrajo tan rápidamente y cerró sus puertas en marzo de 2001. Peter Morville describe su rápido final en una entrevista ${ }^{3}$ como el del canario en la mina de carbón (su muerte avisaba de los enormes problemas que se avecinaban). Desde este punto de vista, la arquitectura de la información caía primero por ser punta de lanza.

\section{«Cuando entraron los jefazos al despa- cho con las tijeras del recorte y nos vie- ron con todas las es- trellas puestas, lo primero que nos pre- guntaron fue qué cla- se de arquitectos éramos»}

Yo, algo menos poético, creo que todo se vino abajo al mismo tiempo (y sin preferencia ni discriminación de disciplinas). Entonces la arquitectura de la información se dio de cara con un problema con el que el profesional de la información se ha encontrado siempre: la dificultad de explicar a otros exactamente y con claridad lo que hacemos y por qué somos importantes para una organización.

En plan guasa: cuando entraron los jefazos al despacho con las tijeras del recorte de personal y nos vieron a la cabeza del desfile envueltos en la bandera de la ia, vestidos de capitán, con todas las estrellas puestas, lo primero que nos preguntaron es qué clase de arquitectos éramos exactamente. A muchos les temblaron los labios y, como resultado, nos volaron la gorra de un revés.
Durante 2001 y 2002 los arquitectos de la información se dispersaron. Algunos volvieron a ocupar puestos de trabajo que habían abandonado con anterioridad. $\mathrm{Mu}-$ chos fueron pasando (en virtud de adquisiciones, etc.) a las consultorías supervivientes. Una buena parte, como es mi caso, decidió que era el momento de establecerse por cuenta propia y seguir trabajando en el web. Muchos, al parecer han dedicado su tiempo a escribir todo lo que saben y más. Una búsqueda reciente en Amazon muestra 254 libros sobre "information architecture" publicados después de 1999, entre ellos la segunda edición del libro de Peter Morville y Lou Rosenfeld.

http://www.amazon.com

\section{La arquitectura de la información hoy}

¿Quiere esto decir que le ha llegado el fin a la arquitectura de la información? Yo no lo creo así. El número de nuevos libros dedicados al tema que utilizan dicho termino parece indicar que ha cuajado y sigue en pie.

Quizá los profesionales que se dieron en llamar "arquitectos de la información" estén ahora un poco desorientados. Eso explica las múltiples iniciativas dirigidas a mantener viva la comunidad de profesionales. Blogs como Community infrastructure for information architects, el blog de Lou Rosenfeld o el de Iaslash.org nos proporcionan un foro de desahogo. Asociaciones como el Asilomar Institute for Information Architecture (AIfIA), o web sites como el de Jesse James Garrett también contribuyen en este sentido. La American Society for Information Science and Technology (Asis\&t) ha organizado la cumbre de arquitectura de la información (Ia summit 2003: information architecture "making connections") en marzo de 2003.

http://www.info-arch.org/ 
http://louisrosenfeld.com/home/blo ug_archivel

http://www.iaslash.org/

http://www.aifia.org/

http://www.jjg.net/

El título "arquitecto de la información" también ha sobrevivido y permanece en el vocabulario de recursos humanos de las empresas americanas. Quizá es ahora uno más, que compite con otros como "especialista en información", "profesional de la información", "experto en usabilidad", "documentalista" y otros. Una búsqueda en Monster identifica 19 anuncios de puesto de trabajo para arquitectos de la información en los EUA en los últimos 60 días.

http://www.monster.com

De alguna manera el arquitecto de la información ha vuelto a casa como el hijo pródigo. Aquí nos encontramos con nuestra vieja amiga: la constante necesidad de demostrar quiénes somos y qué hacemos. La lucha continua por reconocimiento profesional.

¿Y el futuro? Supongo que cualquier opinión vale. ¡Ya nos gustaría a todos poder ver el futuro! Yo creo que nos queda cuerda para rato. Quizá porque esta lucha permanente por demostrar quiénes somos muestra, en mi opinión, tanto una debilidad como nuestra mayor fuerza. Aunque es cierto que ha desaparecido la demanda loca que hubo, también es verdad que persiste intacta la gran necesidad de nuestros servicios. Por un lado, es una realidad que somos unos incomprendidos (y gran parte de quiénes son ajenos a este campo, ni saben de su existencia), por otro la- do sin embargo tenemos la ventaja de que nadie nos marca y podemos movernos con cierta libertad (como arquitectos, aparejadores o albañiles de la información).

Quizá un día el capitán se vuelva a dejar la gorra olvidada en la mesa, y quizá la banda de música pase por la calle en ese momento tocando un pasodoble...

\section{Notas}

1. Richard Saul Wurman. Information architects. Graphis, 1997.

2. Morville, Peter; Rosenfeld, Lou. Information architecture for the world wide web. O'Reilly \& Associates, 1998, March.

3. "Louis Rosenfeld \& Peter Morville interview".

http://www.since1968.com/interviews.cfm? $i d=7$

Jesús Bustamante. Camino Project Inc.

http://www.caminoproject.com 